\title{
Etnografia como possibilidade metodológica para a Ciência da Informação
}

\author{
Jefferson Veras Nunes \\ Bárbara Luisa Ferreira Carneiro \\ Antonio Wagner Chacon Silva \\ Universidade Federal do Ceará, Departamento de Ciências da Informação. Fortaleza, Brasil.
}

\section{CASE REPORT}

\begin{abstract}
Resumo
Objetivo. Abordar a etnografia enquanto possibilidade metodológica para a Ciência da Informação.

Metodologia. Compreende artigo de revisão com base em pesquisa exploratória e bibliográfica.

Resultados. Aponta a necessidade da Ciência da Informação inserir o indivíduo como eixo da problemática informacional, ressaltando a importância da realização de pesquisas pautadas em abordagens qualitativas como um processo pelo qual a área pode ampliar seu escopo investigativo. Nesse sentido, a etnografia contribui com uma perspectiva que reinvidica da Ciência da Informação a preocupação em destacar a experiência ordinária dos indivíduos, atentando para os sentidos que os indivíduos atribuem às suas ações de informação.

Conclusões. Recorrendo à etnografia, a Ciência da Informação pode captar o papel ativo do indivíduo ao ser ou ao estar informado, concebendo, assim, a informação enquanto fenômeno diretamente relacionado à sociedade e à cultura na qual ela é gerada, recepcionada, apropriada e disseminada.
\end{abstract}

Palavras-chave

Ciência da Informação. Etnografia. Metodologia da pesquisa. Pesquisa qualitativa.

\section{Etnography as a methodological possibility for Information Science}

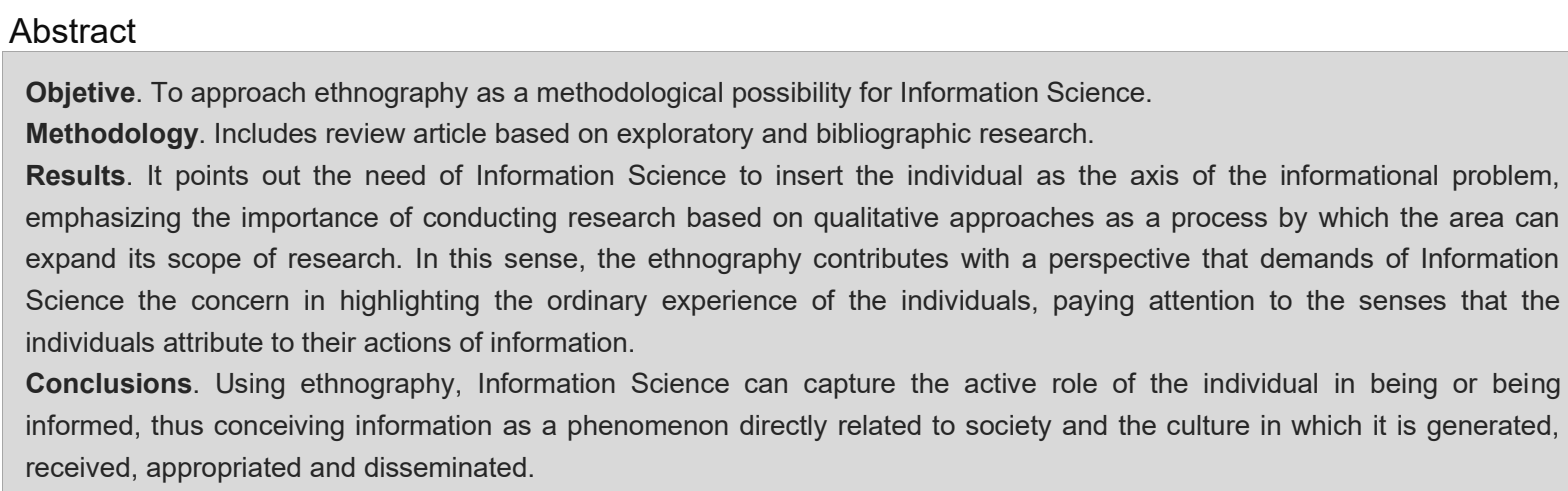

Keywords

Ethnography. Information Science. Research methodology. Qualitative research.

\section{Introdução}

A etnografia é caracterizada como um método de pesquisa qualitativa, sendo, com frequência, adotada em diferentes disciplinas pertencentes às Ciências Sociais e Humanas. Em linhas gerais, o método é aplicado pelo pesquisador para tentar captar, dentre inúmeras coisas, discursos, práticas e performances dos indivíduos participantes de determinada cultura. Nesse sentido, seu objetivo principal é compreender aspectos que podem vir a demarcar desde a identidade dos indivíduos, até o modo como estes se relacionam entre si e com o mundo à sua volta, sempre numa perspectiva particular e nunca totalizante da realidade. 
Em decorrência do caráter plural que a Antropologia atribuiu à etnografia ao adotá-la quase que exaustivamente, muitas definições sobre este método de pesquisa têm sido engendradas. De modo geral, isto tem gerado calorosos debates justamente porque sua ampla utilização promove alguma confusão entre os limites do método e da própria disciplina antropológica, podendo-se questionar se a etnografia seria apenas um método adotado pela Antropologia, ou se a etnografia se constitui ela própria enquanto disciplina autônoma.

Em decorrência disso, o conceito de Angrosino (2009) cabe ser evocado pelo caráter didático por meio do qual o método é apresentado ao pesquisador neófito. De acordo com o autor, "a etnografia é a arte e a ciência de descrever um grupo humano - suas instituições, seus comportamentos interpessoais, suas produções materiais e suas crenças" (ANGROSINO, 2009, p. 30). Nessa mesma perspectiva, Spradley (1979, p. 65) define a etnografia como sendo "[...] a descrição de um sistema de significados culturais de um determinado grupo ou lugar", cujo propósito é compreender determinado fenômeno sociocultural partindo da perspectiva dos próprios sujeitos da pesquisa.

Para estudar determinado grupo e suas singularidades, vários autores salientam a necessidade do pesquisador ir até o campo - no sentido mais estrito da pesquisa empírica - e compartilhar experiências semelhantes às vivenciadas pelos indivíduos pesquisados. O campo, ipso facto, não fornece dados absolutos e objetivos sobre a realidade estudada, mas, sim, "materiais" que se convertem em dados durante o desenrolar da pesquisa. "Materiais" estes que, por sua vez, estão atrelados aos aprofundamentos teóricos empreendidos pelo investigador com o objetivo de auxiliar na interpretação de determinado fenômeno sociocultural.

A etnografia surge como um dos principais métodos adotados pela Antropologia, sendo confundida, por muitos, com a própria ciência que deu origem a ela. Contudo, faz-se necessário destacar que outras áreas também têm se valido da etnografia enquanto método, assim como esta tem despertado o interesse de pesquisadores de diferentes áreas. Como exemplo disso, cabe evocar aqui Lévi-Strauss (1979). No capítulo Olhando para trás, de seu livro Tristes Trópicos, ao escrever sobre sua vocação para a etnografia, afirma: "tal como acontece com as matemáticas ou com a música, a etnografia é uma das raras vocações autênticas. Podemos descobri-la dentro de nós mesmos sem nunca a termos aprendido" (LÉVI-STRAUSS, 1979, p. 49). Etnografia se aprende, na maioria das vezes, praticando-a. Constitui o resultado de um constante exercício da sensibilidade do pesquisador ao analisar a realidade, bem como de sua capacidade de alteridade, de percepção do Outro.

Neste texto, entretanto, ambiciona-se apontar as contribuições da etnografia para a Ciência da Informação. Ao entender método, na esteira de González de Gomez (2000), como sendo uma forma de definir a direção da pesquisa a partir de um domínio epistemológico que acolhe as condições de produção do próprio objeto pesquisado, pode-se defender a etnografia enquanto possibilidade metodológica capaz de captar o papel ativo do indivíduo ao ser ou ao estar informado. A relação entre informação, sociedade e cultura, por sua complexidade, reivindica um olhar sensível e cada vez mais atento ao fato de que a produção, o consumo, a busca, a mediação e o compartilhamento da informação compreendem atividades que afetam diretamente a vida cotidiana, constituindo-se, também, enquanto práticas socioculturais que marcam o cenário informacional contemporâneo.

Não por acaso, mas, sim, como um recurso eminentemente didático, decidiu-se erigir o artigo sobre duas questões fundamentais, a saber: no que consiste a etnografia? Como a etnografia pode se apresentar enquanto possibilidade metodológica à Ciência da Informação? Tais questões não só condensam dúvidas que frequentemente o pesquisador se depara ao se interessar pela etnografia, como, também, referem-se aos desafios e possibilidades do método etnográfico na pesquisa qualitativa, em especial no âmbito da Ciência da Informação.

\section{Metodologia}

Caracterizando-se como um artigo de revisão, a discussão travada aqui acerca da etnografia como possibilidade metodológica para a Ciência da Informação tem suas bases na pesquisa exploratória e na pesquisa bibliográfica. Assim, de acordo com Gil (1994), dentre os propósitos da pesquisa exploratória está o de oferecer, numa perspectiva preliminar, informações sobre o objeto ou fenômeno investigado. Por sua vez, a pesquisa bibliográfica está associada aos procedimentos técnicos adotados e tem como intento viabilizar a compreensão 
de conceitos teóricos relativos a um tema específico ou pertencentes a determinado domínio do conhecimento. A pesquisa bibliográfica possibilita ademais "[...] a utilização de dados dispersos em inúmeras publicações, auxiliando também na construção, ou na melhor definição do quadro conceitual que envolve o objeto de estudo proposto" (LIMA; MIOTO, 2007, p. 40).

Nesse sentido, realiza-se um levantamento em torno das especificidades da pesquisa etnográfica, destacando os procedimentos que devem ser adotados para o seu empreendimento; em seguida, ao se discutir a etnografia enquanto abordagem metodológica para a Ciência da Informação ressalta-se a necessidade de se contemplar aqueles componentes ligados às subjetividades envoltas nas práticas e ações de informação, sublinhando, portanto, "a constituição social dos processos informacionais" (ARAÚJO, 2014b).

Assim, empreende-se uma revisão de literatura sobre etnografia apoiando-se nas considerações de Lima e Mioto (2007), para quem esta deve ser a primeira etapa de uma pesquisa bibliográfica, tendo como principal procedimento técnico utilizado a leitura, pois, segundo as autoras, "é através dela que se pode identificar as informações e os dados contidos no material selecionado, bem como verificar as relações existentes entre eles de modo a analisar a sua consistência" (LIMA; MIOTO, 2007, p. 41). Com base em Salvador (1986), a leitura realizada foi dividida em três etapas, a saber: leitura de reconhecimento, com o objetivo de identificar fontes referentes à temática; leitura exploratória, com a finalidade de confirmar a relevância das fontes escolhidas; e, por fim, leitura crítica e interpretativa, destinada ao ordenamento das informações obtidas de modo a responder às questões formuladas.

\section{No que consiste a etnografia?}

A etnografia tem como uma de suas principais técnicas de pesquisa a observação, a qual implica em tentar perceber, direta ou indiretamente, os indivíduos enquanto seres produtores de cultura. Conforme Hammersley e Atkinson (1995), a etnografia compreende um tipo particular de envolvimento, por parte do pesquisador, na dinâmica do grupo a ser por ele estudo. Segundo os autores, "a participação manifesta ou disfarçada do etnógrafo na atividade das pessoas por longo período de tempo, observando o que acontece, ouvindo o que é dito, fazendo perguntas - de fato, coletando qualquer dado que possa lançar luz nas questões que são foco da pesquisa" (HAMMERSLEY; ATKINSON, 1995, p. 1), deve ter como objetivo se debruçar sobre questões acerca do estilo de vida e da visão de mundo dos indivíduos estudados numa perspectiva que priorize ao máximo o relativismo cultural.

Uma das características que marca o início da etnografia ajuda a defini-la como um método direcionado ao estudo de sociedades distantes, exóticas, requerendo do pesquisador uma atitude de estranhamento e exterioridade em relação às formas culturais pesquisadas. Em seu início, o método etnográfico esteve circunscrito ao universo das ditas "sociedades tradicionais", sendo estas de "pequena escala e de cultura relativamente homogênea” (VELHO, 2004), muitas delas localizadas no outro lado do continente. Todavia, é a partir dos anos 1920 que a etnografia passa a ser adotada enquanto método de pesquisa relevante ao estudo das "sociedades complexas", abrindo espaço para estudos realizados em cenários urbanos (TURETA; ALCADIPANI, 2011).

Para poder captar as informações necessárias ao desenvolvimento de sua pesquisa, o etnógrafo deve realizar uma observação direta e sistemática do fenômeno escolhido por ele como objeto de estudo. Nesse sentido, deve haver por parte do pesquisador um compromisso com os pontos de vista percebidos e estudados (TURETA; ALCADIPANI, 2011), justamente porque seu trabalho resulta na exposição de "[...] dados específicos sobre a vida das pessoas em situações específicas" (SPRADLEY, 1979, p. 13). A natureza da observação pode ser caracterizada como "participante" ou "não-participante", conforme o contexto da pesquisa ou, ainda, orientada por uma opção metodológica do próprio pesquisador.

A técnica da observação pode ser adotada em diferentes situações. Como exemplo disso, Stacy (1977) apresenta três delas: 1) quando a cultura do grupo estudado é avessa à do pesquisador; 2) em contextos nos quais há uma subcultura subjacente à do pesquisador; e, por fim, 3) situações em que pesquisador estuda sua própria cultura. Nesse sentido, ao comentar sobre os diferentes cenários que podem marcar a realização de uma etnografia, Tureta e Alcadipani (2011, p. 212) pontuam: 
No primeiro caso, o pesquisador se lança em um meio com hábitos e costumes completamente diferentes do seu. Um caso clássico foi o do etnógrafo Bronislaw Malinowski (1922/1976), que procurou entender o sistema econômico de trocas dos nativos das ilhas Trobriand, do Pacífico Sul. No segundo caso, o pesquisador se insere em grupo de indivíduos que possuem hábitos e costumes bastante peculiares, dentro da própria cultura do observador. Aqui um exemplo seria o trabalho de William Foote Whyte (1955) [2005], que estudou um grupo de imigrantes italianos pobres, moradores de bairro em cidade dos Estados Unidos. No terceiro, o pesquisador investiga uma organização ou instituição formal de sua própria cultura, como, por exemplo, uma empresa (Stacey, 1977). Esse foi o caso do trabalho de Gideon Kunda (1992), que buscou entender a cultura organizacional da divisão de engenharia de empresa de alta tecnologia.

$\mathrm{Na}$ observação não-participante o pesquisador fica à margem, comportando-se como outsider ou mero observador das dinâmicas culturais levadas a efeito por determinado grupo ou comunidade, alheio aos construtos simbólicos ali desencadeados. Por sua vez, na observação participante defende-se que só é possível compreender os aspectos de uma cultura experimentando-os na própria carne - ou, segundo Magnani (2002), estudando-os "de dentro". Nesse sentido, ao empreender uma etnografia, deve-se "delimitar o campo" e "fazer o campo", expressões que aludem, respectivamente, ao tema ou grupo que será objeto de uma investigação qualitativa, bem como ao seu processo de verificação empírica.

Dentre os pesquisadores que elegeram a etnografia como método de pesquisa, mencionados acima por Tureta e Alcadipani (2011), pode-se destacar o trabalho realizado por Malinowski (1976) entre 1914 e 1918 nas Ilhas Trobriand, na costa oriental da Nova Guiné. Nele, o autor defende que é preciso não apenas observar os "nativos" e registrar sua cultura em um caderno de campo, mas principalmente viver com "eles", buscando, na medida do possível, sentir-se como um "deles". O autor desenvolveu uma abordagem que privilegiava uma aproximação maior entre o pesquisador e os indivíduos pesquisados, mesmo considerando o Outro um ente distante no espaço-tempo de sua cultura. A convivência com os "nativos" constitui um elemento importante para se compreender "de perto" o significado das lógicas particulares de determinada cultura.

No trabalho de William Foote Whyte (2005) acerca de um grupo de imigrantes italianos que habitavam uma área pobre de Eastern City (Boston), pode-se perceber a importância que o autor confere ao ato de observar não só as pessoas em Cornerville (North End), mas também o que elas fazem: "o padrão geral de vida é importante, mas só pode ser construído por meio da observação dos indivíduos cujos padrões configuram esse padrão" (WHYTE, 2005, p. 23). Chama a atenção a maneira por meio da qual o jovem pesquisador, em meados dos anos 1940, se envolve com a realidade social estudada, participando de suas dinâmicas.

Nesse sentido, vale aqui fazer uma alusão breve a outra perspectiva interessante de abordagem sobre formas de "subcultura", a qual foi empreendida pelos Estudos Culturais ao se debruçarem sobre temas envolvendo diferentes grupos existentes na Inglaterra do pós-guerra. Surgidos a partir do Centre for Contemporary Cultural Studies (CCCS), os Estudos Culturais, em sua fase inicial, caracterizaram-se pelo desenvolvimento de uma abordagem que conjugava materialismo histórico e cultura, numa perspectiva histórica, social e antropológica. Algumas das pesquisas desenvolvidas no âmbito do CCCS tinham como objetivo analisar as formas de consumo cultural de grupos intitulados como teds, mods, rastafáris, skinheads e rockers ao construírem modos próprios de resistência, através da música e dos símbolos adotados por eles, às ideologias dominantes, compondo, assim, uma cultura contra-hegemônica.

No trabalho de Gideon Kunda (1992), intitulado Engineering Culture: control and commitment in a high-tech corporation, é realizada uma espécie de etnografia da "nova economia" - ou, nos termos de Castells, no contexto de um capitalismo informacional -, onde o autor tem como campo de pesquisa uma empresa norteamericana do segmento de tecnologias da informação. Kunda se lança ao desafio de analisar, de maneira minuciosa, elementos de uma "cultura organizacional", trazendo detalhes que vão desde as interações sociais existentes no interior da empresa, até relatos de seus funcionários sobre como se dão as tentativas dos líderes em inculcar nos trabalhadores o que pode ser chamado de "ideologia" da corporação.

De acordo com Christine Hine (2000, p. 47), "o etnógrafo não é um simples voyeur ou um observador desengajado, mas é, em certo sentido, um participante compartilhando algumas das preocupações, emoções e compromissos dos sujeitos pesquisados". A etnografia se vale de trabalho de campo como um dos principais recursos para a etapa compreendida como "coleta de dados". No campo, o pesquisador se defronta com 
diferentes modos e estilos de vida, seja essa pesquisa realizada com indivíduos pertencentes às ditas "sociedades tradicionais" ou "sociedades complexas".

Uma questão frequentemente realizada por aqueles que estão a se interessar pelo método etnográfico diz respeito aos procedimentos que devem ser adotados para sua efetiva realização. Embora esta seja uma questão difícil de ser solucionada de forma objetiva, recorrer ao pensamento de Geertz (1989, p. 15) pode viabilizar, mais facilmente, a apreensão do fazer etnográfico, quando o aludido pensador comenta como cada uma de suas etapas deve ser praticada, ao revelar que é necessário ao pesquisador "[...] estabelecer relações, selecionar informantes, transcrever textos, levantar genealogias, mapear campos, manter um diário e assim por diante". Pode-se dizer, ainda, que o método etnográfico permite a adoção de diferentes técnicas de "coleta de dados", tais como, além da observação e da entrevista - procedimentos já consolidados -, a análise documental, o uso de fotografias e demais tipos de imagens visuais, a história de vida dos participantes e vários outros.

Geertz (1989, p. 15) alerta ainda que "[...] não são estas coisas, as técnicas e os processos determinados, que definem o empreendimento [etnográfico]. O que o define é um tipo de esforço intelectual que ele representa". Seguindo uma mesma direção, Magnani (2002, p. 17) salienta que "o método etnográfico não se confunde nem se reduz a uma técnica; pode usar ou servir-se de várias, conforme as circunstâncias de cada pesquisa; ele é antes um modo de acercamento e apreensão do que um conjunto de procedimentos" rigorosamente definidos. $\mathrm{Na}$ prática etnográfica, o pesquisador deve se deixar ser constantemente afetado, seguindo um conhecido conselho de Lévi-Strauss (1979): deixar-se envolver pelo campo.

Ao deixar-se envolver pelo campo o pesquisador "se informa", ou seja, se deixa "formar" pela exposição às "perturbações" oriundas das formas de viver e, porque não, de sentir, peculiares à comunidade em que está imerso com o objetivo de coletar dados, numa captura da teia de significantes e de significados. Isto implica em sofrer perturbações e se tornar informado. Tornar-se informado é tomar nova forma. Forma diferente da anterior, que tornará o pesquisador capaz de descrever o que vivenciou, o que experimentou e o que sentiu.

Tanto Geertz (1989), como Magnani (2002), apontam para os riscos que a etnografia pode acarretar quando tratada como um "manual" ou "guia" metodológico. Em tese, este "manual" ou "guia" possibilitaria ao pesquisador escolher a melhor forma possível de apreender determinado fenômeno e seus aspectos socioculturais. No entanto, contrapondo-se a isso, Geertz (1989) propõe um modelo de análise cultural que se apoia em pressupostos hermenêuticos, os quais possibilitam ao pesquisador realizar uma descrição em profundidade das culturas como "textos" vividos, pensando-as como "teias de significados" que devem ser interpretadas.

O "esforço intelectual" referido por Geertz (1989) como necessário para se interpretar alguns dos aspectos culturais de determinada sociedade, está associado ao que o autor nomeia como "descrição densa". Noção esta apropriada do filósofo Gilbert Ryle e definida a partir do famoso exemplo das piscadelas para poder caracterizar no que consiste a etnografia, apoiando-se, ainda, na ideia defendida por Weber de que o homem vive preso nas teias de significados por ele mesmo tecidas (GEERTZ, 1989). O ato banal de contrair a pálpebra e piscar pode ser interpretado de diferentes maneiras pelo pesquisador, respeitando sempre o significado que os próprios indivíduos praticantes dessa ação vão conferir a ela. Assim, segundo o autor,

Fazer a etnografia é como tentar ler (no sentido de 'construir uma leitura de') um manuscrito estranho, desbotado, cheio de elipses, incoerências, emendas suspeitas e comentários tendenciosos, escrito não com os sinais convencionais do som, mas com exemplos transitórios de comportamento modelado (GEERTZ, 1989, p. 7).

Desde seu surgimento o método etnográfico vem desenvolvendo e colocando em prática uma série de estratégias, conceitos e modelos que, apesar de já terem sofrido inúmeras revisões, críticas e releituras das mais variadas ordens, compõem um repertório capaz de inspirar e fundamentar abordagens sobre objetos até então não privilegiados pela etnografia, ajudando a responder questões bastante atuais.

Nesse sentido, é preciso reconhecer que o método etnográfico se caracteriza mais como um processo a ser construído e adaptado às circunstâncias específicas de cada tipo de investigação. As questões que vão auxiliar no delineamento da pesquisa são definidas levando-se em conta as teorias existentes acerca do fenômeno a ser 
estudado, podendo, também, serem reformuladas durante o trabalho de campo. Em decorrência disso, ao optar pelo método etnográfico, o pesquisador deve evitar definições e conceitos estanques, esquivando-se da formulação a priori de hipóteses, justamente porque, no decorrer da pesquisa, o problema proposto inicialmente será inevitavelmente modificado, conforme sua imersão vai se efetivando.

Assim, ao dissertar acerca das estratégias adotadas pelo pesquisador na produção de conhecimento científico amparado na etnografia, Roberto Cardoso de Oliveira (2000) assinala que o resultado de uma pesquisa etnográfica não significa simplesmente um modo de exposição de um saber específico, mas constitui-se antes numa forma especial de pensar como os indivíduos, através das diversas maneiras como se organizam em sociedade, engendram costumes, crenças, sistemas políticas e práticas culturais, dentre outras coisas. $\mathrm{O}$ referido autor indica que o trabalho de campo é marcado por três questões principais: o "olhar", o "ouvir" e o "escrever". Tais elementos envolvem atos cognitivos que, "além de trazerem em si responsabilidades intelectuais específicas, formam, pela dinâmica de sua interação, uma unidade irredutível” (OLIVEIRA, 2000, p. 12).

O "olhar" constitui uma das primeiras experiências do pesquisador no campo e caracteriza o contato inicial com o objeto de estudo. Contudo, esse "olhar" não é de todo ingênuo, mas norteado por esquemas conceituais e leituras realizadas antes de se proceder com a etapa da "coleta de dados". Para exemplificar, Roberto Cardoso de Oliveira utiliza a ilustração de um pesquisador no início de sua investigação sobre determinado grupo indígena e o que pode chamar a sua atenção ao adentrar numa maloca, moradia coletiva característica da população Túkúna:

\footnotetext{
Essa moradia de tão amplas proporções e de estilo tão peculiar, como, por exemplo, as tradicionais casas coletivas dos antigos Túkúna, do alto rio Solimões, no Amazonas, teriam o seu interior imediatamente vasculhado pelo "olhar etnográfico", por meio do qual toda a teoria que a disciplina dispõe relativamente às residências indígenas passaria a ser instrumentalizada pelo pesquisador, isto é, por ele referida. Nesse sentido, o interior da maloca não será visto com ingenuidade, como mera curiosidade diante do exótico, porém com um olhar devidamente sensibilizado pela teoria disponível. Ao basear-se nessa teoria, o observador bem preparado, como etnólogo, iria olhá-la como objeto de investigação previamente construído por ele, pelo menos em uma primeira prefiguração: passará então a contar os fogos pequenas cozinhas primitivas -, cujos resíduos de cinza e carvão irão indicar que, em torno de cada um, estiveram reunidos não apenas indivíduos, porém pessoas. Portanto, seres sociais, membros de um único "grupo doméstico"; o que dará a informação subsidiária que pelo menos nessa maloca, de conformidade com o número de fogos, estaria abrigada uma certa porção de grupos domésticos, formados por uma ou mais famílias elementares e, eventualmente, de indivíduos "agregados" - originários de outro grupo tribal. Conhecerá, igualmente, o número total de moradores - ou quase - contando as redes dependuradas nos mourões da maloca dos membros de cada grupo doméstico (OLIVEIRA, 2000, p. 19-20).
}

Além do "olhar", Roberto Cardoso de Oliveira (2000) também fala sobre o "ouvir", ressaltando sua importância para a pesquisa qualitativa. Segundo o autor, "tanto o ouvir como o olhar não podem ser tomados como faculdades totalmente independentes no exercício da investigação" (OLIVEIRA, 2000, p. 21), mas, sim, complementares, auxiliando na compreensão de determinadas práticas executadas pelos indivíduos pesquisados.

Questões particulares envolvendo determinadas ações dos indivíduos só podem ser captadas, por exemplo, por meio da entrevista. Não significa dizer que é necessário um ato de "ouvir" puro e simples, ou seja, "ouvir por ouvir", e sim que é preciso saber ouvir. Apesar de se considerar a atenção necessária ao que é dito, selecionando-se as falas que podem satisfazer os objetivos da pesquisa, deve-se tentar sobrepor distinções entre "idiomas culturais" (OLIVEIRA, 2000) presente no distanciamento que, por vezes, há entre o mundo do pesquisador e o dos indivíduos pesquisados. Através da observação e da escuta, por exemplo, é possível o sentido que determinadas ações têm para quem as realiza, assim como construir significações para quem a analisa em sua exterioridade.

Contudo, embora o "olhar" e o "ouvir" sejam imprescindíveis à realização de uma etnografia, Oliveira (2000) afirma também que é através do ato de "escrever" que o pesquisador externa as experiências vividas durante o trabalho de campo. Trabalho este dotado de significativa complexidade, pois envolve não apenas questões técnicas de cunho metodológico, mas, principalmente, por sua dimensão moral e política, além de epistemológica (GEERTZ, 1989; OLIVEIRA, 2000). Ao se debruçar sobre determinado fenômeno sociocultural é 
possível descortinar diferentes domínios do conhecimento humano. O caráter epistêmico de uma etnografia está vinculado tanto ao que o pesquisador é capaz de captar pelo "olhar" e pelo "ouvir", como também pelas teorias que articula aos dados colhidos durante o trabalho de campo no momento de redigir o relatório final da pesquisa.

Assim, mais do que simplesmente seguir procedimentos ou padrões pré-estabelecidos metodologicamente, Malinowski (1976) salienta o fato de que o ofício de etnógrafo requer o desenvolvimento de um saber sensível, o qual possibilita ao pesquisador participar da dinâmica sociocultural do grupo que deseja estudar. Com base nisso, o autor sugeriu três questões essenciais para nortearem o "olhar" e o "ouvir" aos quais Oliveira (2000) faz referência. São elas: o que os nativos dizem sobre o que fazem? O que realmente fazem? O que pensam a respeito do que fazem?

O método etnográfico, portanto, reforça a ideia de que é necessário ao pesquisador estabelecer relações variadas com os indivíduos pesquisados, perspectiva esta que implica num diálogo efetivo entre ambos. Além disso, requer também que se admita que o fenômeno a ser estudado não está isolado, tampouco pode ser construído de maneira antecipada, mas, ao contrário, integra um conjunto de relações em constante transformação. Por esse motivo, é preciso problematizar o objeto a ser estudado a partir de seu contexto social, cultural, político e técnico, dentre outros, buscando compreender tanto os sentidos que os indivíduos dão às suas ações, como às suas vidas, com o intuito de tentar captar os pontos de vista daquelas pessoas que podem vir a integrarem a pesquisa.

\section{Como a ciência da informação pode fazer uso da etnografia?}

Nos últimos anos tem-se instaurado novas possibilidades de pesquisa no campo da Ciência da Informação, em especial a partir da crescente incorporação de métodos da pesquisa qualitativa, possibilitando o desenvolvimento da ideia de que a informação está inscrita na cultura e diretamente relacionada às ações dos indivíduos.

Dentre os diferentes conceitos de informação existentes e adotados na área, a perspectiva que se mostra como a mais apropriada aos objetivos deste texto é aquela que faz menção ao papel ativo atribuído para o indivíduo, na medida em que é o próprio indivíduo quem orienta suas ações para "ser/ estar/ ficar informado" (ILHARCO, 2003). Isto implica na defesa da ideia de que a informação não tem vida própria, nem existência exterior, mas, ao contrário, está assentada nos contextos sociais, culturais, políticos, econômicos e técnicos nos quais os indivíduos estão inseridos (ALMEIDA JÚNIOR, 2009).

O sujeito é inserido em um processo de individualização através de sua exposição à realidade, ocasião em que, ao sofrer perturbações dos demais indivíduos que a integram, passa a formar uma memória, prenhe de traços mnêmicos, que the confere a capacidade de identificar e reconhecer alguns fragmentos dessa realidade e, sequer, de perceber outros de seus traços que venham a se mostrar dissociados daqueles já percebidos em momentos passados.

Essa maneira do operar cognitivo dos indivíduos faz com que eles passem a atribuir significados a essas experiências interativas, as quais, ao serem transformadas em discursos, em seus relatos, demonstram os sentidos, ou propensões de suas percepções passadas, presentes e futuras, mostrando, assim, uma estrutura parcial da rede de sociações em que ele está inserido e, portanto, da capacidade dessa rede informar o individuo, ou seja, dar-lhe certa quantidade e qualidade de forma ou sentido perceptivo e interativo.

Tal perspectiva se faz importante porque possibilita estudar a informação levando-se em conta a influência das interações sociais na sua produção, consumo, busca, mediação e compartilhamento. Atividades estas entendidas enquanto ações cotidianas, logo, carregadas de sentido. Portanto, tomando como base o pensamento de Araújo (2014a), cabe evidenciar duas questões fundamentais: "de um lado, [que] o uso da informação é resultado de uma aplicação, por parte dos sujeitos, de significados dados coletivamente; por outro lado, esse conjunto de referências sociais é construído juntamente pelos sujeitos, no decurso de suas ações" (ARAÚJO, 2014a, p. 62).

Com relativa frequência é possível ler em artigos de revisão ou em textos que se propõem a discussões epistemológicas, que as origens da Ciência da Informação estão ligadas às transformações do período pós- 
guerra e seus significativos desafios à sociedade, suscitando a formulação de paradigmas, amparados, principalmente, numa discussão acerca do crescente volume de informação científica. Não raro, pode-se trazer à baila os artigos de Taylor (1966) e Borko (1968), responsáveis por uma definição um tanto quanto embrionária de Ciência da Informação, a qual caracteriza o campo como sendo derivado ou estando diretamente relacionado à Matemática, Lógica e Computação.

De início, a área incorporou os postulados da Teoria da Informação - também conhecida como Teoria Matemática da Comunicação - para delinear seu objeto de estudo. Nesta, informação é definida como sinal elétrico passível de ser mensurado, tendo como principal território disciplinar para o seu alicerce as Ciências Exatas e Tecnológicas. Esta perspectiva pode ser responsável por ocasionar uma "crise de identidade" durante determinado período na Ciência da Informação (ALMEIDA, 2007), onde, devido a um forte apelo tecnológico, seguido por um aporte quantitativo no tocante ao estudo da informação, não se sabia definir com precisão se a Ciência da Informação pertenceria às Ciências Humanas e Sociais ou Exatas.

Os aspectos semântico e subjetivo da informação não são abordados pela Teoria da Informação, e isto porque seu principal propósito é analisar a quantidade de informação que pode ser enviada de um emissor até um receptor, passando por um canal, com o mínimo de ruído possível. As mensagens comportam-se, portanto, como sinais e são estudadas sob o viés do controle. Assim, de acordo com Shannon (apud LOGAN, 2012, p. $34)$,

\footnotetext{
O problema fundamental da comunicação é reproduzir exata ou aproximadamente em um ponto uma mensagem selecionada em outro ponto. Frequentemente as mensagens têm um significado, isto é, referem-se ou estão correlacionadas a algum sistema com certas entidades físicas ou conceituais. Esses aspectos semânticos da comunicação são irrelevantes para o problema de engenharia. $O$ aspecto significativo é que a mensagem real é selecionada de um conjunto de mensagens possíveis.
}

Apesar da informação conter algum significado, este não se constitui como um elemento essencial à sua definição no âmbito da Teoria da Informação. Nesse sentido, questões sobre como o indivíduo pode se apropriar e fazer uso da informação, por exemplo, são desconsideradas, bem como o contexto social em que ela foi gerada e no qual será utilizada não são elementos importantes à sua compreensão. Contrariando essa ótica, Fernando Ilharco (2003) assinala que, ao enviar ou receber um email, por exemplo, "o foco da nossa atenção não está no email per si mas antes no conteúdo específico que colocamos em cada email e sobretudo nas possibilidades de ação que a nossa familiarização com essa tecnologia nos fornece intuitiva e permanentemente" (ILHARCO, 2003, p. 119).

Contudo, cabe reconhecer que, se por um lado, a Teoria da Informação ocasionou uma visão reducionista acerca da informação enquanto fenômeno, por outro, ela proporcionou com que algo considerado banal e até então ignorado, de modo geral, pela ciência pudesse ser investigado - mesmo que de forma objetiva, constituindo-se em objeto de estudo científico.

Em decorrência de questões suscitadas pela Teoria da Informação, as quais auxiliaram o desenvolvimento de vários subcampos da Ciência da Informação, não causa estranhamento o fato de que a problemática de seu objeto de estudo se expresse repetidas vezes relacionada à expansão das tecnologias de informação. Todavia, vale destacar que sua compreensão enquanto fenômeno não deve se limitar à questão da técnica em si, e, sim, residir nas possibilidades de ação que ela - informação - propicia aos indivíduos em seus diferentes espaços de interação. Mesmo que o contexto pesquisado esteja diretamente marcado pelas tecnologias de informação, cabe questionar não apenas de que maneira as tecnologias reconfiguram o cenário informacional contemporâneo, mas, principalmente, como elas afetam as experiências dos indivíduos em suas ações ordinárias de informação.

A ideia de que as tecnologias atuam como produtora das relações sociais, sendo, também, resultado delas, permite partir do pressuposto de que, ao serem diretamente marcadas pela presença humana e pelos efeitos da cultura, devem ser destituídas de qualquer ideia que as tome enquanto mera artificialidade para poderem ser entendidas como artefatos que se revestem de múltiplos significados no plano do simbólico. Informação e cultura são, portanto, duas das palavras-chave do estudo dos seres humanos no mundo e em seus mundos. 
Nesse sentido, faz-se necessário estudar a informação numa perspectiva ampla, compreendida a partir de aspectos socioculturais dos indivíduos, levando em conta os espaços e contextos nos quais se encontram inseridos. Isto porque nem a informação está isolada, tampouco o indivíduo. Percebê-la como algo que independente do contexto é semelhante a olhar para uma figura isolando-a do seu fundo. Quando o fundo muda, altera-se também o significado da própria figura (ILHARCO, 2003). Um termo importante para se compreender a informação é processo. Processo alude a movimento, e entender a informação como processo significa levar em conta não só o modo como sua natureza tem se tornado cada vez mais híbrida e volátil, como, também, enquanto fenômeno sociocultural, o que fomenta o surgimento de diferentes linguagens, experiências, práticas e dinâmicas no mundo contemporâneo.

Apesar de não haver uma definição consensual acerca do conceito de cultura, a perspectiva de Geertz (1989) se mostra como uma alternativa relevante aos propósitos deste texto. Para o autor, cultura se refere a um "padrão de significados transmitido historicamente, incorporado em símbolos, um sistema de concepções herdadas expressas em formas simbólicas por meio das quais os homens se comunicam, perpetuam e desenvolvem seu conhecimento em relação à vida" (GEERTZ, 1989, p. 103). Cultura, portanto, não deve se caracterizar como algo ao qual podem ser atribuídos casualmente os acontecimentos, mas sim um contexto, ou seja, algo dentro do qual se pode descrever e interpretar os símbolos pelos quais se orientam os indivíduos para definirem cotidianamente suas ações e comportamentos.

Com base nisso, cultura pode ser compreendida como aquilo que é distintivo - seja local ou global -, onde o significado é construído e renovado para além de um controle consciente dos indivíduos, ou seja, organizandose dentro de mundos intersubjetivos socialmente construídos. Em seu livro "Futuros Antropológicos: redefinindo a cultura na era tecnológica", Michael Fischer (2011) aponta caminhos para pesquisas em contextos inter e transdiciplinares nos quais a tecnologia constitui-se como um campo fértil de investigação. Para ele, cultura pode ser entendida enquanto algo relacional - ou, como prefere Geertz (1989), como uma "teia" - cujas partes não podem ser modificadas sem afetar as outras, tendo seu caráter continuamente transformado pelas tecnociências.

A proposta de um conceito de cultura readaptado ao atual cenário informacional reconhece que este conceito cresce em múltiplas camadas históricas de especificações e diferenciações. Através dele novas realidades podem ser percebidas, permitindo o estudo de espaços interativos e institucionais dentro das atuais formas de sociabilidade. Nesse sentido, Michael Fischer (2011) defende que a análise cultural deve seguir a "perspectiva de joalheiro". Perspectiva esta que permite observar desde pontos locais de interconexão cultural, até relações multi-situadas em rede, por exemplo. Portanto, conforme salienta o autor, sem uma noção relacional de cultura a ação social pode ser reduzida a pura instrumentalidade.

A etnografia possibilita à Ciência da Informação inserir o indivíduo como eixo da problemática informacional. Com isso, permite ao pesquisador direcionar uma atenção especial aos aspectos intersubjetivos ligados ao modo como se dá a relação entre indivíduo e informação em diferentes contextos sociais.

Desse modo, a Ciência da Informação pode abarcar situações plurais que envolvem o que ela própria tomou como objeto de estudo, ou seja, a informação. A partir de abordagens qualitativas, a área pode se debruçar sobre realidades diversas, não se limitando a clientelas específicas ou ao contexto dos serviços e sistemas de informação (cuja preocupação se volta à coleta, representação e disseminação da literatura científica), mas, ampliando seu escopo, atividades relacionadas com a necessidade, busca e uso da informação, se percebidas tomando como base as motivações e construtos sociais dos próprios indivíduos, vêm a constituir um prisma interessante de estudo.

A etnografia, portanto, contribui com uma perspectiva que reinvidica da Ciência da Informação a preocupação em destacar a experiência ordinária dos indivíduos. Tal perspectiva evidencia a relevância de se estudar a informação direcionando o olhar para o cotidiano, tanto quanto aos contextos formais e profissionais, atentando para os sentidos que os indivíduos atribuem às suas ações de informação. 


\section{Considerações finais}

A etnografia oferece uma rica contribuição à Ciência da Informação no tocante à superação de dicotomias que, de certa forma, têm atuado promovendo certo reducionismo teórico e empírico do fenômeno informacional. Com frequência, a relação entre indivíduos e informação é abordada sob um enfoque pragmático, centrando sua atenção, na maioria das vezes, na dinâmica e constituição dos espaços formais de atuação - especialmente, contextos acadêmicos e profissionais -, cujo olhar se volta à identificação de padrões por meio do uso de parâmetros, modelos e outros indicadores de caráter objetivo.

Nesse sentido, através da etnografia, pode-se conferir destaque aos processos que se efetivam para além dos suportes, possibilitando o rompimento com a lógica linear que tem continuamente caracterizado a informação. Dessa forma, questões referentes às subjetividades, comportamentos, práticas e ações de informação desenvolvidas pelos sujeitos no dia a dia, a partir dos mais diferentes espaços pelos quais transitam e interagem, podem ser efetivamente contempladas, promovendo, assim, maior inserção da Ciência da Informação ao contexto de pesquisa das Ciências Sociais, com a finalidade de ampliar os modos de abordagens sobre a informação enquanto objeto de pesquisa.

Portanto, uma Ciência da Informação plural é factível de ser empreendida, principalmente, ao se considerar a informação como algo relacional, por meio da qual preocupada diferentes dimensões da natureza humana podem ser abordadas. Nesse sentido, faz-se necessário considerar a informação enquanto fenômeno gregário, logo, como algo que existe a partir do indivíduo, da sociedade e da cultura na qual é concebida, recepcionada, apropriada e propalada.

\section{Referências}

ALMEIDA, M. A. Informação, cultura e sociedade: reflexões sobre a ciência da informação a partir das ciências sociais. In: Informação e contemporaneidade: perspectivas. LARA, M. L. G.; FUJINO, A; NORONHA, D. P. (Orgs). Recife: Néctar, 2007.

ALMEIDA JÚNIOR, O. F. Mediação da informação e múltiplas linguagens. Tendências da pesquisa brasileira em Ciência da Informação, Brasília, v. 2, n. 1, p. 89-03, jan./dez. 2009.

ANGROSINO, M. Etnografia e observação participante. Porto Alegre: Artmed, 2009.

ARAÚJO, C. A. A. Fundamentos da Ciência da Informação: correntes teóricas e o conceito de informação. Perspectivas em Gestão \& Conhecimento, João Pessoa, v. 4, n. 1, p. 57-79, jan./jun. 2014a.

ARAÚJO, C. A. A. O que é Ciência da Informação? Informação \& Informação, Londrina, v. 19, n. 1, p. 01-30, jan./abr. 2014b.

BORKO, H. Information science: what is it? American Documentation, v. 19, n. 1, p. 3-5, jan. 1968.

DUPUY, J. P. Nas origens das ciências cognitivas. São Paulo: UNESP, 1996.

FISCHER, M. Futuros Antropológicos: redefinindo a cultura na era tecnológica. Rio de Janeiro: Zahar, 2011.

GEERTZ, C. A interpretação das culturas. Rio de Janeiro: Zahar, 1989.

GIL, A. C. Métodos e técnicas de pesquisa social. São Paulo: Atlas, 1994.

GÓMEZ, M. N. L. G. L. Metodologia de pesquisa no campo da ciência da informação. DataGramaZero, v. 1, n. 6, 2000.

HAMMERSLEY, M.; ATKINSON, P. Ethnography: principles in practice. London: Routledge, 1995.

HINE, C. Virtual Ethnography. London: Sage, 2000.

ILHARCO, F. Filosofia da informação: uma introdução à informação como fundação da acção, da comunicação e da decisão. Lisboa: Universidade Católica, 2003.

KUNDA, G. Engineering culture: control and commitment in a high-tech corporation. Philadelphia: Temple University Press, 1992.

LÉVI-STRAUSS, C. Tristes trópicos. Lisboa: Edições 70, 1979 
LIMA, T. C. S. de; MIOTO, R. C. T.. Procedimentos metodológicos na construção do conhecimento científico: a pesquisa bibliográfica. Revista Katálysis, Florianópolis, v. 10, n. esp, p. 37-45, 2007.

LOGAN, R. K. Que é informação: a propagação da organização na biosfera, na simbolosfera, na tecnosfera e na econosfera. Rio de Janeiro: Editora Contraponto, 2012.

MAGNANI, J. G. C. De perto e de dentro: notas para uma etnografia urbana. Revista brasileira de Ciências Sociais, São Paulo, v. 17, n. 49 , p. 11-29, June 2002.

MALINOWSKI, B. Os argonautas do pacífico ocidental: um relato do empreendimento e da aventura dos nativos nos arquipélagos da nova guiné melanésia. São Paulo: Abril, 1976.

OLIVEIRA, Roberto Cardoso de. O trabalho do antropólogo. Brasília: Paralelo 15; São Paulo: UNESP, 2000.

SALVADOR, A. D. Métodos e técnicas de pesquisa bibliográfica. Porto Alegre: Sulina, 1986.

STACEY, M. Methods of social research. Oxford: Pergamon Press, 1977.

SPRADLEY, J. The ethnographic interview. Forth Worth: Hancourt Brace Jovanovich College, 1979.

TAYLOR, R. S. Professional aspectos of information science and technology. Annual Review of Information Science and Technology, v. 1, p. 15-40, 1966.

TURETA, C.; ALCADIPANI, R. Entre o observador e o integrante da escola de samba: os não-humanos e as transformações durante uma pesquisa de campo. Revista de administração contemporânea, Curitiba, v. 15, n. 2, p. 209-227, Apr. 2011

VELHO, G. Individualismo e cultura: notas para uma antropologia da sociedade contemporânea. Rio de Janeiro, Zahar, 1981.

WHYTE, W. F. Street corner society. Chicago: University Chicago Press, 2005. 


\section{Dados dos autores}

Jefferson Veras Nunes

Doutor em Ciência da Informação pela Universidade Estadual Paulista "Júlio de Mesquita Filho" (UNESP).

Professor do Departamento de Ciências da Informação da Universidade Federal do Ceará (UFC).

jefferson.veras@yahoo.com.br

\section{Bárbara Luisa Ferreira Carneiro}

Mestre em Ciência da Informação pelo Programa de Pós-Graduação em Ciência da Informação da Universidade Federal do Ceará (UFC).

barbaracarneiro_@hotmail.com

Antonio Wagner Chacon Silva

Doutor em Educação pela Universidade Federal do Ceará (UFC). Professor do Departamento de Ciências da Informação da Universidade Federal do Ceará (UFC).

ciberwagner@yahoo.com.br

Received - Recebido: 2017-08-28

Accepted - Aceitado: 2019-08-01

\section{(cc) $\mathrm{Br}$}

This work is licensed under a Creative Commons Attribution 4.0

United States License.

\section{ULIS D-Sulle}

This journal is published by the University Library System of the University of Pittsburgh as part of its D-Scribe Digital Publishing Program and is cosponsored by the University of Pittsburgh Press. 